\title{
Chemoradiotherapy Versus Chemotherapy for Localized Gastric Cancer: A Mini Review
}

\author{
Daniel da Motta Girardi ${ }^{*}$, Gabriela Oliveira Mendes² \\ 'Department of Oncology, Hospital Sírio Libanês, Brazil \\ ${ }^{2}$ Hospital de Base do Distrito Federal, Brasília, Brazil
}

Article Info

\section{Article Notes}

Received: July 07, 2018

Accepted: August 16, 2018

\section{${ }^{*}$ Correspondence:}

Dr. Daniel da Motta Girardi, SGAS II St. de Grandes Áreas Sul 613 Conjunto E 95 - Asa Sul, Brasília - DF, 70200-001, Brazil; Telephone No: +55(61) 30448888;

Email: danielmgirardi@gmail.com

(c) 2018 Girardi DM. This article is distributed under the terms of the Creative Commons Attribution 4.0 International License.
Abstract

Curative treatment for localized gastric cancer involves a multidisciplinary approach that includes surgery and chemotherapy with or without radiotherapy. In the past decades several studies have shown survival benefit of postoperative and perioperative treatments in comparison with surgery alone. Only a few trials have compared directly chemotherapy with chemoradiotherapy without a clear benefit favoring one strategy over another. In the absence of a standard approach, the choice of the best treatment is individualized and varies by geographic region and the preference of the institution where the patient is being treated. This review summarizes what is new in the treatment of localized gastric cancer and seeks to deeply analyze chemotherapy and chemoradiotherapy strategies.

\section{Introduction}

The incidence of gastric cancer has been declining over the past century; however, it is still an important cause of cancerrelated death in the world and currently the most prevalent cancer in East Asia ${ }^{1}$. Curative strategies for localized gastric cancer (LGC) require surgery. However, even after resection, the local recurrence rate is approximately $24 \%$ to $54 \%^{2}$. Strategies to reduce the rate of locoregional recurrence have been evaluated over the last few decades, and several studies have shown a benefit from chemotherapy (CT) and chemoradiotherapy (CRT).

Despite recent advances, no treatment regimen has been clearly superior to the other, and we still do not have a standard approach for LGC patients. The objective of this study is to analyze the current evidence on the topic and to discuss future perspectives.

\section{Postoperative strategies}

The phase III Intergroup 0116 (INT-0116) trial randomized 556 patients for observation alone or 5-fluorouracil (5-FU)-based CRT. The experimental arm significantly increased overall survival (OS) (median OS of 35 vs. 27 months; $\mathrm{P}=0.0046$ ) and disease-free survival (DFS) (27 vs. 19 months; $\mathrm{P}<0.001$ ) compared with surgery alone (Table 1$)^{3}$. The limitations of this study are that only $10 \%$ of patients underwent D2 dissection, and the benefit was mostly seen in locoregional relapse. Therefore, the addition of radiotherapy might have only compensated for a suboptimal surgery technique. The Cancer and Leukemia Group B (CALGB) 80101 is another phase III trial that evaluated adjuvant CRT. This trial randomized 546 patients to postoperative 5-FU-based CRT or CT with epirubicin, cisplatin, and infusional 5-FU (ECF) before and after CRT with 5-FU. 
Table 1. Phase III trials of postoperative strategies.

\begin{tabular}{|c|c|c|c|c|}
\hline Study & $\mathbf{N}$ & Experimental Arm & Control Arm & Results \\
\hline Intergroup Study 0116 [3] & 556 & Surgery + 5-FU/LV/RT & Surgery Alone & $\begin{array}{l}\text { median OS of } 35 \text { vs. } 27 \text { months } \\
\text { (HR: } 1.32 ; P=0.0046)\end{array}$ \\
\hline CALGB 80101 [4] & 546 & $\begin{array}{l}\text { Surgery + ECF before and after CRT } \\
\text { with 5-FU }\end{array}$ & Surgery + 5-FU/LV/RT & $\begin{array}{l}\text { 5-year OS } 44 \% \text { vs. } 44 \% \\
\text { (HR: } 0.98 ; P=0.69 \text { ) }\end{array}$ \\
\hline ACTS-GC [6] & 1059 & Surgery (D2 ressection) + S1 & Surgery alone (D2 ressection) & $\begin{array}{l}5 \text {-year OS } 71.7 \% \text { vs } 62.1 \\
\text { (HR } 0.669 ; 95 \% \mathrm{Cl}, 0.540 \text { to } 0.828 \text { ) }\end{array}$ \\
\hline CLASSIC Trial [7] & 1035 & $\begin{array}{l}\text { Surgery (D2 ressection) + capecitabina } \\
\text { and oxaliplatina }\end{array}$ & Surgery alone (D2 ressection) & $\begin{array}{l}\text { 3-year DFS } 74 \% \text { vs } 59 \% \\
\text { (HR 0.56; } P<0.0001 \text { ) }\end{array}$ \\
\hline ARTIST Trial [8] & 458 & $\begin{array}{l}\text { Surgery (D2 ressection) + capecitabine } \\
\text { and cisplatin plus RT with capecitabine }\end{array}$ & $\begin{array}{l}\text { Surgery (D2 ressection) + } \\
\text { capecitabine and cisplatin }\end{array}$ & $\begin{array}{l}\text { 5-year OS of } 75 \% \text { vs. } 73 \% \\
\text { (HR: } 1.130 ; P=0.5272)\end{array}$ \\
\hline
\end{tabular}

Abbreviations: 5-FU: 5-Fluorouracil; LV: leucovorin; RT: radiotherapy; OS: overall survival; DFS: disease-free survival; CRT: chemoradiotherapy; HR: hazard ratio; $\mathrm{Cl}$ : confidence interval.

There were no survival difference, with both arms reaching 5 -year OS of 44\% (hazard ratio [HR]: $0.98 ; \mathrm{P}=0.69$ ) and no difference in 5-year DFS (39\% for FU-based CRT and 37\% for ECF arm, HR 0.96; $\mathrm{P}=0.94$ ) (Table 1) ${ }^{4}$.

The idea of including a targeted therapy to CRT in HER-2 positive gastric or gastroesophageal junction (GEJ) cancer was evaluated in the TOXAG study. The trial enrolled 34 patients submitted to curative gastrectomy with D2 lymph node dissection. Patients received capecetabine and oxaplatin with trastuzumab for three cycles followed by radiotherapy with capecetabine for five weeks and trastuzumab for up to a year (17 cycles). The authors concluded that the regimen was safe and tolerable and median OS was not yet reached ${ }^{5}$.

Chemotherapy regimens have shown a survival benefit in D2-dissected patients compared to observation. The Japanese ACTS-GC trial randomized 1059 patients undergoing gastrectomy with D2 lymph node resection to receive $\mathrm{S} 1$ after surgery or surgery alone. The 5-year OS was $71.7 \%$ for those who received S1 versus $61.1 \%$ in the surgery alone group (HR, 0.669; 95\% confidence interval [CI], 0.540 to 0.828 ) (Table 1$)^{6}$. The CLASSIC trial randomized 1035 patients to receive 8 cycles of capecitabine plus oxaliplatin CT or remain under observation after surgery. The 3-year DFS was higher in the group receiving CT (74\% vs 59\%, HR 0.56; $\mathrm{P}<0.0001)$ (Table 1$)^{7}$.

Few data are available comparing head-to-head CT and CRT adjuvant strategies. The ARTIST trial compared adjuvant CT, based on capecitabine and cisplatin, with CRT in patients submitted to gastric resection and D2 lymphadenectomy. Seven-year follow-up of these patients demonstrated a lower locoregional recurrence rate for the CRT arm but a similar OS. The locoregional relapse was $13 \%$ in the CT arm and 7\% in the CRT arm ( $\mathrm{P}=0.0033)$. The 5 -year OS was $75 \%$ and $73 \%$ for CRT and CT, respectively $(\mathrm{P}=0.484)$ (Table 1$)^{8}$.

While prospective trials failed to show any difference between CT and CRT, some nonprospective trials have reported controversial results. A meta-analysis conducted by a Chinese group evaluated 960 patients from four studies (excluding CRITICS but including ARTIST) and showed benefits in terms of DFS (HR $=0.73 ; P=0.002)$ and the locoregional recurrence rate $(\mathrm{RR}=0.50 ; P=0.0005)$ for patients receiving postoperative CRT, but failed to demonstrate any significant difference in OS $(\mathrm{HR}=0.91 ; P=0.34)^{2}$. A retrospective study evaluated 21.472 patients with LGC using the Surveillance and Epidemiology and End Results (SEER) database. Patients were classified using the American Joint Committee on Cancer 6th edition. For those in Stage I, the surgery alone group had the most favorable outcomes (HR: 0.67; CI: 0.60$0.76)$, whereas those in stages II, III and nonmetastatic stage IV were mostly benefit by postoperative CRT 9 . Another large retrospective trial using the National Cancer Database evaluated 3.656 patients and demonstrated a small survival benefit for CRT after a propensity scorematched analysis (5-year OS of $45 \%$ vs $42 \%$ for CRT vs perioperative CT; HR 0.886; $\mathrm{P}=0.033$ ). The benefit of CRT was mostly pronounced in patients with $\mathrm{R} 1$ resection and was not significantly different regarding the extent of lymphadenectomy despite the fact that most of these patients $(75.4 \%)$ had suboptimal lymphadenectomy ${ }^{10}$. An additional two retrospective trials failed to show a significant difference between the two strategies. A Chinese trial evaluated adjuvant CRT (INT-0116 regimen) and CT alone (fluoropyrimidine alone or in combination with oxaliplatin) and found a similar median OS (51.0 vs 48.6 months for CRT and CT, respectively; $P=0.251)^{11}$. A similar Brazilian study evaluated adjuvant CRT with the INT-0116 regimen versus adjuvant platinum-fluoropyrimidine CT. There was no difference in OS (HR 0.73; $\mathrm{P}=0.212$ ) even after a propensity score-matched analysis (HR 0.80; $\mathrm{P}=0.47)^{12}$.

Patient selection may play a role in detecting a difference between these strategies, if any actually exist. A subgroup analysis of the ARTIST trial ${ }^{8}$ showed that for patients with pathological involvement of lymph nodes, the 3-year DFS was prolonged in the CRT arm compared with the CT arm $(77.5 \%$ vs. $72.3 \% ; \mathrm{P}=0.0365)$. This strategy is currently being prospectively evaluated in the 
ARTIST-II trial (NCT01761461). A microscopically positive margin (R1) after gastrectomy can be found in $2-20 \%$ of patients $^{13,14}$, and there is a rationale to add postoperative radiotherapy to lower the locoregional recurrence. However, no prospective trial has evaluated this specific scenario and retrospective data have shown inconsistent results. A retrospective Dutch cohort analyzed 409 cases of patients with LGC and R1 resections. A significant difference in median OS between no-CRT and CRT groups were found (24 months vs. 13 months; for CRT and noCRT, respectively; $\mathrm{P}=0.003$ ), which was confirmed by a propensity score analysis (HR 0.57; $95 \%$ CI $0.38-0.88)^{15}$. Another retrospective study evaluated 114 patients with LGC with R1 gastrectomy. Patients received CRT or CT consisting of platinum-fluoropyrimidine with or without epirubicin. No difference was observed in OS. The 3-year OS rates of the CRT and CT groups were $49.6 \%$ vs $39.4 \%$, respectively $(\mathrm{P}=0.20)^{16}$.

\section{Preoperative strategies}

Preoperative treatment has the potential to demonstrate in vivo tumor sensitivity, to early treat micrometastasis and to promote tumor regression leading to a higher chance of R0 resection. Recent studies evaluating preoperative CT have shown impressive results. In the MAGIC trial, which enrolled 503 patients to perioperative ECF versus observation alone, the 5-year survival rate favored the ECF arm $(36.3 \%$ and $29.5 \%$ for perioperative CT and observation, respectively, HR 0.75; $\mathrm{P}=0.009$ ) (Table 2) ${ }^{17}$. A French phase III trial randomized 224 to perioperative treatment with cisplatin and infusional 5-FU or surgery alone. The 5-year OS favored the experimental arm $(38 \%$ vs. 24\%; HR: 0.69; $\mathrm{P}=0.02$ ) (Table 2) ${ }^{18}$. The FLOT4 trial enrolled 704 patients to a triplet perioperative regimen consisting of docetaxel, 5-FU and oxaliplatin (FLOT) and compared it with the MAGIC trial anthracycline-based regimen. The FLOT regimen improved OS (median OS, 35 vs.
50 months for the MAGIC regimen and FLOT, respectively; HR 0.77; $P=0.012$ ). The 3 -year OS rate was $48 \%$ with the MAGIC regimen and $57 \%$ with FLOT (Table 2$)^{19}$.

The addition of monoclonal antibodies to perioperative CT was evaluated in the MAGIC-B/ST03 trial, which randomized 1.063 patients with localized esophagogastric adenocarcinoma to perioperative CT alone consisting of epirrubicin, cisplatin and capecetabine (ECX) or the same regime plus the anti-angiogenic agent bevacizumab. Interestingly, the 5-year OS did not differ between the two arms (50.3\% vs. $48.1 \%$ for ECX and ECX plus bevacizumab respectively, HR 1.08; $\mathrm{P}=0.36$ ) (Table 2) ${ }^{20}$.

The European Organization for Research and Treatment of Cancer (EORTC) 40954 trial evaluated the strategy of neoadjuvant treatment. This phase III trial planned to enroll 360 patients but the enrollment was closed early duo to poor accrual. A total of 144 patients with gastric or GEJ adenocarcinoma were randomized to neoadjuvant cisplatin and 5-FU CT or surgery alone. The study couldn't demonstrate a survival benefit with neoadjuvant treatment (2-year OS rate of $72.7 \%$ with CT vs. $69.9 \%$ with surgery alone, HR 0.84; $\mathrm{P}=0.466$ ) (Table 2) ${ }^{21}$.

The role of radiotherapy in the perioperative strategy is still not clear. The CRITICS study randomized 788 patients receiving preoperative epirubicin, cisplatin or oxaliplatin, and capecitabine CT followed by gastric resection with D1 lymphadenectomy, to receive postoperative CT (with the same preoperative regimen) or CRT with capecitabine and cisplatin. The final data did not show a difference in OS between the two regimens (median OS was 43 vs. 37 months in the CT and CRT groups, respectively; HR 1.01; $\mathrm{P}=0.90$ ) (Table 2) ${ }^{22}$. The phase III POET trial was terminated early duo to poor accrual and randomized 119 patients with GEJ adenocarcinoma to neoadjuvant CT with cisplatin and FU or neoadjuvant cisplatin and FU followed by CRT with cisplatin and etoposide. The CRT arm had a

Table 2. Phase III trial of preoperative strategies.

\begin{tabular}{|c|c|c|c|c|}
\hline Study & $\mathbf{N}$ & Experimental Arm & Control Arm & Findings \\
\hline MAGIC Trial [17] & 503 & ECF perioperative + Surgery & Surgery Alone & $\begin{array}{l}5 \text {-year OS } 36.3 \% \text { vs. } 29.5 \% \\
\text { (HR 0.75; } P=0.009 \text { ) }\end{array}$ \\
\hline FNCLCC/FFCD [18] & 224 & $\begin{array}{l}\text { Cisplatin and infusional 5-FU perioperative + } \\
\text { Surgery }\end{array}$ & Surgery Alone & $\begin{array}{l}\text { 5-year OS } 38 \% \text { vs. } 24 \% \text {; } \\
\text { (HR: 0.69; } P=0.02 \text { ) }\end{array}$ \\
\hline FLOT4-AIO Trial [19] & 704 & FLOT perioperative + Surgery & ECF perioperative + Surgery & $\begin{array}{l}\text { Median OS } 50 \text { vs. } 35 \text { months } \\
\text { (HR 0.77; P= 0.012) }\end{array}$ \\
\hline MAGIC-B/ST03 trial [20] & 1.063 & ECX plus Bevacizumab perioperative & ECX & $\begin{array}{l}5 \text {-year OS } 48.1 \% \text { vs. } 50.3 \% \\
\text { (HR 1.08; } P=0.36 \text { ) }\end{array}$ \\
\hline EORTC 40954 [21] & 144 & Neoadjuvant cisplatin and 5-FU & Surgery Alone & $\begin{array}{l}\text { 2-year OS of } 72.7 \% \text { vs. } 69.9 \% \\
\text { (HR 0.84; } P=0.466 \text { ) }\end{array}$ \\
\hline CRITICS Trial [22] & 788 & $\mathrm{ECX} / \mathrm{EOX}+$ Surgery $+\mathrm{CX}$ plus RT & ECX/EOX + Surgery + ECX/EOX & $\begin{array}{l}\text { Median OS } 37 \text { vs. } 43 \text { months } \\
\text { (HR 1.01; } p=0.90)\end{array}$ \\
\hline POET Trial [23] & 119 & $\begin{array}{l}\text { neoadjuvant cisplatin and 5-FU followed by } \\
\text { CRT with cisplatin and etoposide }\end{array}$ & $\begin{array}{l}\text { Neoadjuvant cisplatin and } \\
\text { 5-FU }\end{array}$ & $\begin{array}{l}\text { 5-year OS of } 39.5 \% \text { vs. } 24.4 \% \\
\text { ( HR 0.65; } P=0.055 \text { ) }\end{array}$ \\
\hline
\end{tabular}

Abbreviations: 5-FU: 5-Fluorouracil; OS: overall survival; HR: hazard ratio, CRT: chemoradiotherapy 
higher rate of pathologic complete response $(14.3 \%$ vs. $1.9 \%, \mathrm{P}=0.03$ ), but the 5 -year OS did not statistically differ between both arms $339.5 \%$ for CRT arm vs. $24.4 \%$ for CT arm, HR 0.65; P=0.055) (Table 2) [23].

\section{Conclusion and future directions}

Whether the addition of postoperative radiotherapy brings some benefit when added to CT is still controversial. Recent studies have shown similar OS results in patients with D2 lymph node dissection. To date, no prospective data have demonstrated that any subgroup of patients may actually benefit from CRT over CT. We are waiting for the results of ARTIST-II, which is prospectively comparing both strategies for patients with pathological lymph nodes. The rationale of offering CRT for patients with R1 surgery has not been prospectively evaluated, and retrospective data are controversial.

Perioperative CT strategies have shown impressive results in recent phase III trials. The addition of radiotherapy in this scenario is still not clear, with disappointing results from CRITICS trial. However, future trials will help clarify this question. The TOPGEAR study (NCT01924819) is a phase III trial randomizing patients with LGC to perioperative ECF alone versus preoperative ECF with chemoradiation followed by postoperative ECF. Recent published data have shown that this strategy is safe and feasible ${ }^{24}$. Additionally, the CRITICS II trial (NCT02931890) is currently recruiting patients and aims to compare the best neoadjuvant treatment by randomizing patients into three preoperative arms: CT alone, CT followed by CRT or CRT.

\section{References}

1. Karimi P, Islami F, Anandasabapathy S, et al. Gastric cancer: descriptive epidemiology, risk factors, screening, and prevention Cancer epidemiology, biomarkers \& prevention : a publication of the American Association for Cancer Research, cosponsored by the American Society of Preventive Oncology. 2014 May; 23(5): 700-13. PubMed PMID: 24618998. Pubmed Central PMCID: PMC4019373. Epub 2014/03/13. eng.

2. Zhou Ml, Kang M, Li Gc, et al. Postoperative chemoradiotherapy versus chemotherapy for R0 resected gastric cancer with D2 lymph node dissection: an up-to-date meta-analysis. World Journal of Surgical Oncology. 2016 08/08 11/06/received 07/20/accepted;14:209. PubMed PMID: PMC4977857.

3. Smalley SR, Benedetti JK, Haller DG, et al. Updated analysis of SWOG-directed intergroup study 0116: a phase III trial of adjuvant radiochemotherapy versus observation after curative gastric cancer resection. Journal of clinical oncology : official journal of the American Society of Clinical Oncology. 2012 Jul 1; 30(19): 2327-33. PubMed PMID: 22585691. Pubmed Central PMCID: PMC4517071. Epub 2012/05/16. eng.

4. Fuchs CS, Niedzwiecki D, Mamon HJ, etal. AdjuvantChemoradiotherapy With Epirubicin, Cisplatin, and Fluorouracil Compared With Adjuvant Chemoradiotherapy With Fluorouracil and Leucovorin After Curative Resection of Gastric Cancer: Results From CALGB 80101 (Alliance). Journal of clinical oncology official journal of the American Society of Clinical Oncology. 2017 Nov 10; 35(32): 3671-7. PubMed PMID 28976791. Pubmed Central PMCID: PMC5678342. Epub 2017/10/05. eng.
5. Abali H, Yalcin S, Onal C, et al. A study of the combination of oxaliplatin, capecitabine, and trastuzumab and chemo-radiotherapy in the adjuvant setting in operated patients with HER2+ gastric or gastroesophageal junction cancer (TOXAG study). Journal of Clinical Oncology. 2018; 36(4_suppl): 26.

6. Sasako M, Sakuramoto S, Katai H, et al. Five-year outcomes of a randomized phase III trial comparing adjuvant chemotherapy with S-1 versus surgery alone in stage II or III gastric cancer. Journal of clinical oncology : official journal of the American Society of Clinical Oncology. 2011 Nov 20; 29(33): 4387-93. PubMed PMID: 22010012. Epub 2011/10/20. eng.

7. Bang YJ, Kim YW, Yang HK, et al. Adjuvant capecitabine and oxaliplatin for gastric cancer after D2 gastrectomy (CLASSIC): a phase 3 openlabel, randomised controlled trial. Lancet (London, England). 2012 Jan 28; 379(9813): 315-21. PubMed PMID: 22226517. Epub 2012/01/10. eng.

8. Park SH, Sohn TS, Lee J, et al. Phase III Trial to Compare Adjuvant Chemotherapy With Capecitabine and Cisplatin Versus Concurrent Chemoradiotherapy in Gastric Cancer: Final Report of the Adjuvant Chemoradiotherapy in Stomach Tumors Trial, Including Survival and Subset Analyses. Journal of clinical oncology : official journal of the American Society of Clinical Oncology. 2015 Oct 1; 33(28): 3130-6. PubMed PMID: 25559811. Epub 2015/01/07. eng.

9. Seyedin S, Wang PC, Zhang $Q$ et al. Benefit of Adjuvant Chemoradiotherapy for Gastric Adenocarcinoma: A SEER Population Analysis. Gastrointestinal cancer research : GCR. 2014 May; 7(3-4): 8290. PubMed PMID: 25276261. Pubmed Central PMCID: PMC4171970. Epub 2014/10/03. eng.

10. Stumpf PK, Amini A, Jones BL, et al. Adjuvant radiotherapy improves overall survival in patients with resected gastric adenocarcinoma: A National Cancer Data Base analysis. Cancer. 2017 Sep 1; 123(17): 3402-9. PubMed PMID: 28513823. Epub 2017/05/18. eng.

11. Peng J, Wei Y, Zhou F, et al. D2-resected stage IIIc gastric cancer patients benefit from adjuvant chemoradiotherapy. Cancer Medicine. 2016 09/26 04/01/received 07/26/revised 07/27/ accepted;5(10):2773-80. PubMed PMID: PMC5083730.

12. Girardi DM, de Lima MA, Pereira GCB, et al. Chemoradiotherapy versus chemotherapy as adjuvant treatment for localized gastric cancer: a propensity score-matched analysis. BMC Cancer. 2018 Apr 3; 18(1): 378. PubMed PMID: 29614980. Pubmed Central PMCID: PMC5883367. Epub 2018/04/05. eng.

13. Raziee HR, Cardoso R, Seevaratnam R, et al. Systematic review of the predictors of positive margins in gastric cancer surgery and the effect on survival. Gastric cancer : official journal of the International Gastric Cancer Association and the Japanese Gastric Cancer Association. 2012 Sep; 15 Suppl 1: S116-24. PubMed PMID: 22138928. Epub 2011/12/06. eng.

14. Kim SH, Karpeh MS, Klimstra DS, et al. Effect of microscopic resection line disease on gastric cancer survival. Journal of gastrointestinal surgery : official journal of the Society for Surgery of the Alimentary Tract. 1999 Jan-Feb; 3(1): 24-33. PubMed PMID: 10457320. Epub 1999/08/24. eng.

15. Stiekema J, Trip AK, Jansen EP, et al. Does adjuvant chemoradiotherapy improve the prognosis of gastric cancer after an $\mathrm{r} 1$ resection? Results from a dutch cohort study. Annals of surgical oncology. 2015 Feb; 22(2): 581-8. PubMed PMID: 25164039. Epub 2014/08/29. eng.

16. Zhou ML, Li GC, Yang W, et al. Adjuvant chemoradiotherapy versus adjuvant chemotherapy for R1 resected gastric cancer: a retrospective cohort study. The British journal of radiology. 2018 Jun; 15: 20180276. PubMed PMID: 29906235. Epub 2018/06/16. eng.

17. Cunningham D, Allum WH, Stenning SP, et al. Perioperative chemotherapy versus surgery alone for resectable gastroesophageal cancer. The New England journal of medicine. 2006 Jul 6; 355(1): 1120. PubMed PMID: 16822992. Epub 2006/07/11. eng. 
18. Ychou M, Boige V, Pignon JP, et al. Perioperative chemotherapy compared with surgery alone for resectable gastroesophageal adenocarcinoma: an FNCLCC and FFCD multicenter phase III trial. Journal of clinical oncology : official journal of the American Society of Clinical Oncology. 2011 May 1; 29(13): 1715-21. PubMed PMID: 21444866. Epub 2011/03/30. eng.

19. Al-Batran SE, Homann N, Schmalenberg H, et al. Perioperative chemotherapy with docetaxel, oxaliplatin, and fluorouracil/leucovorin (FLOT) versus epirubicin, cisplatin, and fluorouracil or capecitabine (ECF/ECX) for resectable gastric or gastroesophageal junction (GEJ) adenocarcinoma (FLOT4-AIO): A multicenter, randomized phase 3 trial. Journal of Clinical Oncology. 2017; 35(15_suppl): 4004.

20. Cunningham D, Stenning SP, Smyth EC, et al. Peri-operative chemotherapy with or without bevacizumab in operable oesophagogastric adenocarcinoma (UK Medical Research Council ST03): primary analysis results of a multicentre, open-label, randomised phase 2-3 trial. The Lancet Oncology. 2017 Mar; 18(3): 357-70. PubMed PMID: 28163000. Pubmed Central PMCID: PMC5337626. Epub 2017/02/07. eng.

21. Schuhmacher C, Gretschel S, Lordick F, et al. Neoadjuvant chemotherapy compared with surgery alone for locally advanced cancer of the stomach and cardia: European Organisation for
Research and Treatment of Cancer randomized trial 40954. Journal of clinical oncology : official journal of the American Society of Clinical Oncology. 2010 Dec 10; 28(35): 5210-8. PubMed PMID: 21060024. Pubmed Central PMCID: PMC3020693. Epub 2010/11/10. eng.

22. Cats A, Jansen EPM, van Grieken NCT, et al. Chemotherapy versus chemoradiotherapy after surgery and preoperative chemotherapy for resectable gastric cancer (CRITICS): an international, open-label, randomised phase 3 trial. The Lancet Oncology. 2018 May; 19(5): 616-28. PubMed PMID: 29650363. Epub 2018/04/14. eng.

23. Stahl M, Walz MK, Riera-Knorrenschild J, et al. Preoperative chemotherapy versus chemoradiotherapy in locally advanced adenocarcinomas of the oesophagogastric junction (POET): Longterm results of a controlled randomised trial. European journal of cancer (Oxford, England : 1990). 2017 Aug; 81: 183-90. PubMed PMID: 28628843. Epub 2017/06/20. eng.

24. Leong T, Smithers BM, Haustermans K, et al. TOPGEAR: A Randomized, Phase III Trial of Perioperative ECF Chemotherapy with or Without Preoperative Chemoradiation for Resectable Gastric Cancer: Interim Results from an International, Intergroup Trial of the AGITG, TROG, EORTC and CCTG. Annals of surgical oncology. 2017 Aug; 24(8): 22528. PubMed PMID: 28337660. Epub 2017/03/25. eng. 